\title{
Achiasmate male meiosis in two Cymatia species (Hemiptera, Heteroptera, Corixidae)
}

\author{
Desislava Stoianova', Snejana Grozeva', Nikolay Simov², Valentina Kuznetsova ${ }^{3}$ \\ I Institute of Biodiversity and Ecosystem Research, Bulgarian Academy of Sciences, 1 Tsar Osvoboditel, Sofia \\ 1000, Bulgaria 2 National museum of Natural History, Bulgarian Academy of Sciences, 1 Tsar Osvoboditel, \\ Sofia 1000, Bulgaria 3 Zoological Institute, Russian Academy of Sciences, Universitetskaya nab. 1, St. Peter- \\ sburg 199034, Russia
}

Corresponding author: Desislava Stoianova (d.st.stoianova@gmail.com)

Academic editor: N. Golub | Received 30 September 2015 | Accepted 8 November 2015 | Published 19 November 2015

http://zoobank.org/54196143-A697-4E8D-B8EE-63734277870D

Citation: Stoianova D, Grozeva S, Simov N, Kuznetsova V (2015) Achiasmate male meiosis in two Cymatia species (Hemiptera, Heteroptera, Corixidae). In: Lukhtanov VA, Kuznetsova VG, Grozeva S, Golub NV (Eds) Genetic and cytogenetic structure of biological diversity in insects. ZooKeys 538: 95-104. doi: 10.3897/zookeys.538.6722

\begin{abstract}
The karyotype and male meiosis, with a particular focus on the presence or absence of chiasmata between the homologs, were studied in the water boatman species Cymatia rogenhoferi (Fieber) and C. coleoptrata (Fabricius) (Corixidae, Cymatiainae). It is shown that the species have $2 \mathrm{n}=33\left(28 \mathrm{~A}+2 \mathrm{~m}+\mathrm{X}_{1} \mathrm{X}_{2} \mathrm{Y}\right)$ and $2 n=24(20 \mathrm{~A}+2 \mathrm{~m}+\mathrm{XY})$ respectively, post-reduction of sex chromosomes, and achiasmate meiosis of an alignment type in males. Cytogenetic and some morphological diagnostic characters separating Cymatia Flor from the rest of Corixidae are discussed.
\end{abstract}

\section{Keywords}

Karyotype, m-chromosomes, sex chromosome post-reduction, spermatocyte meiosis, morphology, Nepomorpha, Corixoidea 


\section{Introduction}

The Corixoidea, known as water boatmen, are moderately large to small aquatic insects, belonging to the true bug infraorder Nepomorpha. According to Schuh and Slater (1995), Corixoidea include the only family Corixidae, with six subfamilies: Corixinae, Cymatiainae, Diaprepocorinae, Heterocorixinae, Stenocorixinae, and Micronectinae. Nieser (2002a, b) raised Diaprepocorinae and Micronectinae to a family rank, meaning that Corixoidea is comprised of three families only: Corixidae, Micronectidae, and Diaprepocoridae. The validity of Nieser's (2002b) system was criticised by Andersen and Weir (2004), but accepted by the majority of other authors (Tinerella 2008, Grozeva et al. 2008, Konopko et al. 2010, Weirauch and Schuh 2011, Fent et al. 2011). Chromosome data is currently available for Micronectidae as well as for the corixid subfamilies Corixinae and Cymatiainae. In Micronectidae all four hitherto studied species were reported to have achiasmate male meiosis and no m-chromosomes: three species of Micronecta Kirkaldy, 1897 display $2 \mathrm{n}=24(22 \mathrm{~A}+\mathrm{XY})$, while one species of Tenagobia Bergroth, 1899 has $2 \mathrm{n}=30(28+\mathrm{XY})$ (Ituarte and Papeschi 2004, Grozeva et al. 2008). In Corixinae, all 30 studied has species from eight genera were shown to share common characteristics in males: chiasmate meiosis, sex chromosome post-reduction, presence of a pair of m-chromosomes, and karyotype with $2 \mathrm{n}=24(20+2 \mathrm{~m}+\mathrm{XY})$ (Ueshima 1979, Waller and Angus 2005, Bressa and Papeschi 2007). Cymatiainae consist of two genera, Cymatia Flor, 1860 with dispersed Holarctic and Oriental distributions and the monotypic Cnethocymatia Jansson, 1982 from northern Australia and New Guinea (Štys and Jansson 1988). For the only studied species of Cymatiainae, Cymatia bonsdorff (Sahlberg, 1819), the karyotype with $2 \mathrm{n}=26(24+\mathrm{XY})$ was reported with no information on $\mathrm{m}$-chromosomes and presence/absence of chiasmata in male meiosis (Slack 1938, Southwood and Leston 1959).

In meiosis, the chiasmata are known to tie homologous chromosomes together until their separation in the reductional division. However, in some animal groups, instead of chiasma formation, an achiasmate type of meiosis is observed, being, as a rule, restricted to the heterogametic sex (White 1973). In true bugs, when achiasmate meiosis presents, it seems to be stable and marks taxa at the rank of family (Grozeva et al. 2008a). Until the present time, this meiotic pattern has been found in seven families of Heteroptera, belonging to the infraorders Nepomorpha, Leptopodomorpha and Cimicomorpha (see Kuznetsova et al. 2011 for references).

In the present paper, the karyotype and male meiosis of other two Cymatia species, C. rogenhoferi (Fieber, 1864) and C. coleoptrata (Fabricius, 1777), were studied. The focal point of this work was to clarify the presence or absence of chiasmata in spermatocyte meiosis of these species.

\section{Material and methods}

Five males of Cymatia rogenhoferi and two males of $C$. coleoptrata were collected by light trap and hydrobiological net in different localities (Table 1). Males of C. coleoptrata were fixed in 3:1 fixative (96\% ethanol:glacial acetic acid mixture) in the field 
Table I. Material used for chromosome analysis

\begin{tabular}{c|c|c}
\hline Species & $\begin{array}{c}\text { Number of } \\
\text { analysed males }\end{array}$ & Locality and date of collection \\
\hline $\begin{array}{c}\text { Cymatia } \\
\text { rogenhoferi }\end{array}$ & 5 & $\begin{array}{r}\text { Kazakhstan, Taukum Sands, near Topar River, eastern from Topar } \\
\text { Village, 363m a. s. l., } 45^{\circ} 02^{\prime} 12^{\prime \prime N}, 074^{\circ} 58^{\prime} 33^{\prime \prime E} \text {, light trap, } \\
31.05 .2015, \text { leg. N. Simov and F. Konstantinov }\end{array}$ \\
\hline C. coleoptrata & 1 & $\begin{array}{c}\text { Bulgaria, Danube River, marsh Malak Preslavets, 20m a. s. l., } \\
44^{\circ} 05^{\prime} 43^{\prime \prime} \mathrm{N}, 026^{\circ} 50^{\prime} 23^{\prime \prime} \mathrm{E}, 13.07 .2014, \text { leg. D. Stoianova }\end{array}$ \\
\hline C. coleoptrata & 1 & $\begin{array}{c}\text { Bulgaria, Danube River, Srebarna lake, 13m a. s. l., } 44^{\circ} 06^{\prime} 47^{\prime \prime} \mathrm{N}, \\
027^{\circ} 03^{\prime} 34^{\prime \prime E}, 12.07 .2014, \text { leg. D. Stoianova }\end{array}$ \\
\hline
\end{tabular}

immediately after capturing. Males of C. rogenhoferi were fixed in the field in 95\% ethanol for subsequent sequencing, and the abdomen was transferred in 3:1 fixative for chromosome analysis, as it has been done recently by Nokkala et al. (2015) for Cacopsylla myrtilli (W. Wagner, 1947) (Psylloidea). The gonads were dissected out and squashed in a small drop of $45 \%$ acetic acid. The cover slip was removed using dry ice. Slides were dehydrated in fresh fixative (3:1) and air dried. The preparations were stained using Schiff-Giemsa method (Grozeva and Nokkala 1996).

The chromosomes were analysed under light microscope (Axio Scope A1 - Carl Zeiss Microscope) at 100× magnification and documented with a ProgResMFcool Jenoptik AG digital camera. All preparations and remains of the specimens are stored at the Institute of Biodiversity and Ecosystem Research (IBER), BAS in Sofia, Bulgaria.

\section{Results}

\section{Cymatia rogenhoferi, $2 \mathrm{n}=33\left(28 \mathrm{~A}+2 \mathrm{~m}+\mathrm{X}_{1} \mathrm{X}_{2} \mathrm{Y}\right)$}

The testes of the adult males were full of sperm, with a small number of well-synchronised dividing cells. No spermatogonial metaphases were observed. When condensing from a diffuse stage (Figs 1a, b, c), the autosomal bivalents consisted of side-by-side aligned homologous chromosomes without chiasmata, and the sex chromosomes appeared as a positively heteropycnotic body. No diplotene and diakinesis were present. At metaphase I (MI), the bivalents laid parallel to the equatorial plane, with the homologous chromosomes facing opposite poles without any sign of chiasmata. Clearly, male meiosis of this species is achiasmate. Both MI and MII were radial (Figs 2, 3). At MI, 14 autosomal bivalents and three univalent sex chromosomes (two X and one $\mathrm{Y}$ ) formed a ring with, a pair of very small and negatively heteropycnotic m-chromosomes inside. In contrast to MI, the MII ring was formed by 14 autosomes and one mchromosome, while the sex chromosomes formed a pseudo-trivalent placed inside the ring. The $\mathrm{Y}$ chromosome was clearly larger than each of the two $\mathrm{X}$ chromosomes (Fig. 3 ). The first division was thus reductional for the autosomes and m-chromosomes, but equational for the sex chromosomes (post-reduction). The chromosome formula of $C$. rogenhoferi was determined as $2 \mathrm{n}=33\left(28 \mathrm{~A}+2 \mathrm{~m}+\mathrm{X}_{1} \mathrm{X}_{2} \mathrm{Y}\right)$. 


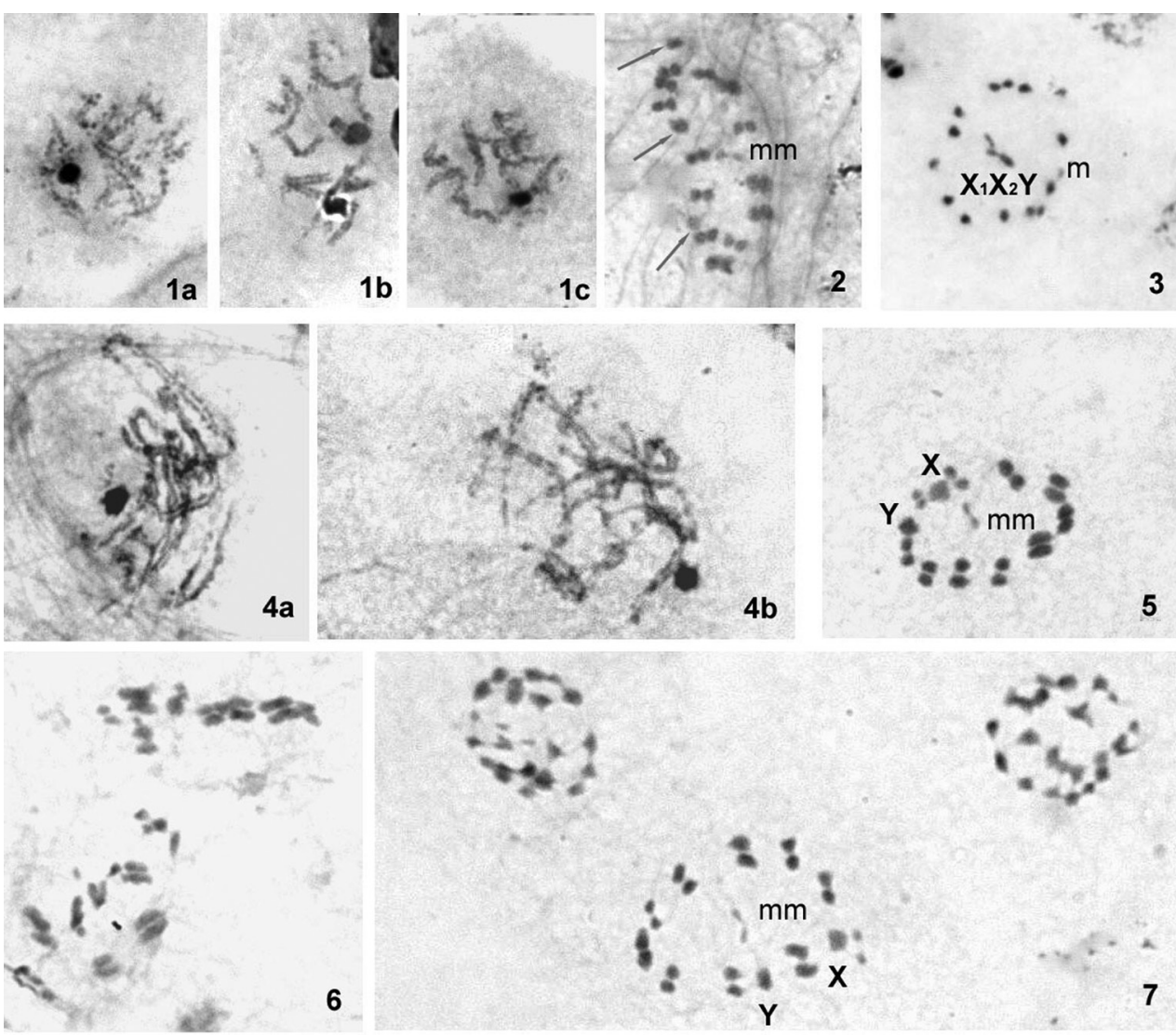

Figures I-7. Male meiosis in Cymatia species. I-3 C. rogenhoferi: a-c early condensation stages $\mathbf{2}$ MI from the pole. The bivalents (consisting of two side-by-side aligned chromosomes facing the opposite poles) and three univalent sex chromosomes (two $\mathrm{X}$ and one $\mathrm{Y}$ ) form a ring, with a pair of very small and negatively heteropycnotic $\mathrm{m}$-chromosomes in its centre $\mathbf{3}$ MII. The autosomes and $\mathrm{m}$-chromosome form a ring, with pseudo-trivalent of the sex chromosomes in its centre 4-7 C. coleoptrata: $\mathbf{a}, \mathbf{b}$ early condensation stages $\mathbf{5} \mathrm{MI}$ from the pole. The bivalents (consisting of two side-by-side aligned chromosomes) and two univalent sex chromosomes ( $\mathrm{X}$ and $\mathrm{Y}$ ) form a ring, with a pair of very small and negatively heteropycnotic $\mathrm{m}$-chromosomes in its centre $\mathbf{6} \mathrm{MI}$ from the equator. The homologous autosomes can be seen lying parallel 7 late MI and AI plates. Scale bar $=10 \mu \mathrm{m}$.

\section{C. coleoptrata, $2 \mathrm{n}=24(20 \mathrm{~A}+2 \mathrm{~m}+\mathrm{XY})$}

The behaviour of chromosomes during the first spermatocyte division was quite similar to that in C. rogenhoferi. Unfortunately, we found no second division stages in the two males explored here. When condensing from the diffuse stage (Figs 4a, b), the autosomal bivalents consisted of parallel aligned homologous chromosomes without traces of chiasmata, and the sex chromosomes appeared as a positively heteropycnotic body. No diplotene and diakinesis were observed. At metaphase I (MI), the bivalents were aligned parallel to the equatorial plane, with the homologous chromosomes facing op- 
posite poles without any signs of chiasmata. The MI plates were radial (Fig. 5), with 10 autosomal bivalents and two univalent sex chromosomes (X and $\mathrm{Y}$ ) forming a ring and a pair of very small and negatively heteropycnotic $\mathrm{m}$-chromosomes placing inside it. The X chromosome was larger than the Y. Side by side association of homologous autosomes was still preserved at MI (Figs 5, 6) and anaphase I (AI) (Fig. 7), when the homologs moved in parallel to the opposite poles. Clearly, male meiosis of this species is achiasmate. The first division was reductional for the autosomes and $\mathrm{m}$-chromosomes, but equational for the sex chromosomes (post-reduction).

The chromosome formula of $C$. coleoptrata was determined as $2 n=24(20 A+2 m+X Y)$.

\section{Discussion}

The main goal of this paper was to address the cytogenetic features of two species of $C y$ matia and compare them with those encountered within the superfamily Corixoidea. This entailed at least four related issues, namely: 1) whether the karyotypes are conservative in respect to chromosome number and sex chromosome system, 2) whether m-chromosomes are present, 3) whether the post-reduction of sex chromosomes is present, and 4) whether the chiasmata are formed in male meiosis. Both Corixidae and Micronectidae are known to be characterised by an XY sex chromosome system and an inverted sequence of $\mathrm{X}$ and $\mathrm{Y}$ chromosome divisions in spermatocyte meiosis, i.e. the sex chromosome post-reduction (for references see Ueshima 1979, Ituarte and Papeschi 2004, Waller and Angus 2005, Bressa and Papeschi 2007, Grozeva et al. 2008). Post-reduction means that the sex chromosomes behave as univalents during the first round of meiosis and undergo equational separation at AI whereas they form a pseudobivalent at MII and undergo reductional segregation at anaphase II. The species here studied, $C$. rogenhoferi and C. coleoptrata, were found to share the same characteristics with Corixidae and Micronectidae, i.e. an XY system and the sex chromosome postreduction in male meiosis. Multiple $\mathrm{X}_{1} \mathrm{X}_{2} \mathrm{Y}$ mechanism found in $C$. rogenhoferi might have originated by fragmentation of the initial $\mathrm{X}$ chromosome. The inverted sequence of sex chromosome divisions in spermatocyte meiosis is characteristic of the Heteroptera as a whole (Ueshima 1979), with rare exceptions (e.g. Golub et al. 2015). Other cytogenetic features, including chromosome numbers and presence or absence of $\mathrm{m}$ chromosomes, whose origin, nature and significance are questionable (e.g. Nokkala 1986, Kuznetsova et al. 2011), and presence or absence of chiasmata in male meiosis, are distributed variously among different taxa of Corixidae and Micronectidae.

In Corixinae, each of 30 species studied display ten pairs of autosomes, a pair of very small $\mathrm{m}$-chromosomes, and $\mathrm{X}$ and $\mathrm{Y}$ chromosomes: the karyotype formula of these species can be expressed as $2 \mathrm{n}=24(20 \mathrm{~A}+2 \mathrm{~m}+\mathrm{X}+\mathrm{Y})$. Meiosis is of a standard chiasmate type in males (Ueshima 1979, Waller and Angus 2005, Bressa and Papeschi 2007). Compared to Corixinae, the family Micronectidae is less well studied. The karyotypes are currently known in Micronecta (Dichaetonecta) scholtzi (Fieber, 1860), M. (Micronecta) poweri (Douglas \& Scott, 1869), and M. (Micronecta) griseola Hor- 
vath, 1899, each with $2 \mathrm{n}=24(22 \mathrm{~A}+\mathrm{XY})$ (Grozeva et al. 2008), and in Tenagobia (Fuscagobia) fuscata (Stål, 1859), with 2n = $30(28+\mathrm{XY})$ (Ituarte and Papeschi 2004). Based on the data available, Micronectidae differ from Corixinae in that they have alternative numbers of autosomes and no m-chromosomes. Furthermore, the species studied in Micronectidae show the achiasmate meiosis in males. Cymatia rogenhoferi and C. coleoptrata studied in this paper, were found to have $2 \mathrm{n}=33\left(28 \mathrm{~A}+2 \mathrm{~m}+\mathrm{X}_{1} \mathrm{X}_{2} \mathrm{Y}\right)$ and $2 \mathrm{n}=24(20 \mathrm{~A}+2 \mathrm{~m}+\mathrm{XY})$ respectively and achiasmate meiosis of an alignment type in males. In another Cymatia species, C. bonsdorff (Sahlberg, 1819), studied by Slack (1938) and later by Southwood and Leston (1959), the karyotype of $2 \mathrm{n}=26(24+$ $\mathrm{XY}$ ) was reported. Unfortunately, the authors provided no information on the special features of meiosis, including sex chromosomes' behaviour. Thus, on the basis of the current state of knowledge, the Cymatiainae share a presence of $\mathrm{m}$-chromosomes with Corixinae, while the absence of chiasmata is shared with Micronectidae. Due to their very small size and negative heteropycnosis during meiosis, $\mathrm{m}$-chromosomes are easily overlooked by researchers, and subsequently information about the distribution of these puzzling structures in different true bug taxa can hardly be used for inferences.

The first (reductional in the majority of organisms) division involves several meiosisspecific events the most important being the formation of chiasmata, the points of genetic crossing-over, between homologous chromosomes. When meiosis is achiasmate and chiasmata are not formed, no diplotene or diakinesis stages can be recognised. The existence of achiasmate meiosis in phylogenetically unrelated true bug families, i.e. Micronectidae from the infraorder Nepomorpha (Ituarte and Papeschi 2004, Grozeva et al. 2008), Saldidae from the Leptopodomorpha (Nokkala and Nokkala 1983), and in several families of the Cimicomorpha (Nokkala and Nokkala 1984, Nokkala and Nokkala 1986a, b, Nokkala and Grozeva 2000, Grozeva and Nokkala 2002), argue for its repeated and independent origin in the evolution of Heteroptera. At the same time, the achiasmate meiosis in true bugs is probably of very ancient origins, since some divergence has occurred in its cytological characteristics during the evolution (Nokkala and Grozeva 2000, Grozeva et al. 2008). Consequently, true bugs evolved a diversity of achiasmate meiosis types that include a variety starting from an alignment type to a colochore type, including an intermediate type (Nokkala and Nokkala 1983, Nokkala and Nokkala 1984, Nokkala and Nokkala 1986a, b, Kuznetsova et al. 2007). Comprehensive classification of different types of achiasmate meiosis can be found in Kuznetsova et al. (2011). The most common type is achiasmate meiosis of the alignment type characterised by the tight side-by-side alignment of homologous chromosomes throughout prophase until MI. Meiosis of this type has been described in the Saldidae, Nabidae, Anthocoridae, Microphysidae, Corixoidea: Micronectidae (for references see Grozeva et al. 2008), and now also in another corixid group, the Cymatiainae (present study).

The Cymatiainae were erected for the first time as a separate taxon (as Cymatiini) in Corixidae on the basis of the shape and hairiness of the pala, the chitinisation of the pharynx, the length of maxillary stylets, and their position against pharynx (Walton in Hutchinson 1940). Later, the labium structure, the position of the labial sensilla, and absence of the strigil and stridulation mechanism, and the ability of sound production, 
Table 2. Key diagnostic characters used to distinguish Cymatiainae from the rest of Corixidae

\begin{tabular}{c|c}
\hline Cymatiainae & Corixidae \\
\hline $\begin{array}{c}\text { Labium without transverse sulcations } \\
\begin{array}{c}\text { Absence of transverse pattern of distribution } \\
\text { of the labial sensilla }\end{array}\end{array}$ & Labium with transverse sulcations \\
\hline Nodal furrow absent & Nodal furrow present \\
\hline Pala elongate, nearly cylindrical in both sexes & Female pala spoon-shaped; male pala variable \\
\hline Pala without pegs & Pala with pegs \\
\hline Pala in both sexes without palm & Claw of hind leg inserted subapically \\
\hline Claw of hind leg inserted apically & Presence of seta close to the claw' basis \\
\hline Absence of seta close to the claw' basis & Usually with strigil \\
\hline Strigil absent & $\begin{array}{c}\text { Stridulation by rubbing peg fields on the anterior } \\
\text { femur against the side of the head, females of some } \\
\text { species also able to stridulate }\end{array}$ \\
\hline Unable to stridulate & Chiasmate male meiosis \\
\hline Achiasmate male meiosis &
\end{tabular}

as well as some other characters of the pala and embolium (Table 2) were added to the diagnosis (Jansson 1973, 1986, Schuh and Slater 1995, Nieser 2002b, Chen et al. 2005, Hädicke 2012, Broźek 2013a, b, 2014).

In different phylogenetic studies on Corixoidea (Zimmermann 1986, Mahner 1993, Hebsgaard et al. 2004, Hädicke 2012, Broźek 2014) the position of Cymatiainae varies from being considered a sister group of Corixidae s. str. (Corixinae + Heterocorixinae) or a basal taxon (together with Diaprepocoridae) in the whole superfamily Corixoidea. It has repeatedly been shown that the absence of chiasmata during spermatocyte meiosis is evolutionarily stable in true bugs, and marks taxa at the rank of family (for references see Grozeva et al. 2008, Kuznetsova et al. 2011). In this context, the finding of achasmate meiosis in Micronectidae (Grozeva et al. 2008) clearly supports the familial status of this group, earlier proposed by Nieser (2002a, b). Both achiasmate meiosis and a number of morphological diagnostic characters (Table 2) distinguish Cymatiainae from the rest of Corixidae. However, more comprehensive studies on morphological and cytogenetic aspects of Corixoidea as a whole are required to decide on the rank that should be assigned to Cymatiainae. The special focus must be on the genus Cnethocymatia from the same subfamily, the genus Diaprepocoris Kirkaldy, 1897 considered the most basal taxon of Corixoidea, and the genus Stenocorixa Horváth, 1926 showing morphological similarities with Cymatiainae (Hebsgaard et al. 2004, Hädicke 2012, Brożek 2014).

\section{Acknowledgements}

This study was financially supported by the grant from the Russian Science Foundation no. 14-14-00541 to the Zoological Institute of Russian Academy of Sciences (for 
VK) and by the grant OPOS 20-UPRR/17.04.2014 with RIOSW-Russe (for DS). We want to thank Fedor Konstantinov (St. Petersburg University, St. Petersburg), Borislava Gyosheva and Mila Ihtimanska (IBER-BAS, Sofia) for the valuable help in collecting the specimens. We are greatly indebted to Yuri Popov (Borissiak Paleontological Institute, Moscow), Seppo Nokkala (University of Turku, Turku), Pavel Štys (Charles University, Prague), Nico Nieser (Naturalis Biodiversity Centre, Leiden) for reviews and valuable comments and remarks.

\section{References}

Andersen NM, Weir TA (2004) Australian water Bugs. Their biology and identification (Hemiptera-Heteroptera, Gerromorpha \& Nepomorpha). Entomonograph Apollo Books, Stenstrup 14: 1-344.

Bressa MJ, Papeschi AG (2007) New contributions for the study of Corixoidea: cytogenetic characterization of three species of Sigara Fabricius from Argentina and the plausible mechanism of karyotype evolution within Nepomorpha. Revista de la Sociedad Entomológica Argentina 66(3/4): 81-89.

Brożek J (2013a) A comparison of external and internal maxilla and mandible morphology of water bugs (Hemiptera: Heteroptera: Nepomorpha). Zootaxa 3635(4): 340-378. doi: 10.11646/zootaxa.3635.4.2

Brożek J (2013b) Comparative analysis and systematic mapping of the labial sensilla in the Nepomorpha (Heteroptera: Insecta). The Scientific World Journal 2013: 1-44. [Article ID 518034] doi: $10.1155 / 2013 / 518034$

Brożek J (2014) Phylogenetic Signals from Nepomorpha (Insecta: Hemiptera: Heteroptera) Mouthparts: Stylets Bundle, Sense Organs, and Labial Segments. The Scientific World Journal 2014: 1-30. [Article ID 237854] doi: 10.1155/2014/237854

Chen P-p, Nieser N, Zettel H (2005) The aquatic and semiaquatic bugs (Insecta: Heteroptera: Nepomorpha \& Gerromorpha) of Malesia. Fauna Malesiana Handbook 5. Brill N.V., Academic Publishers, Leiden, 546 pp.

Fent M, Kment P, Çamur-Elipek B, Kirgiz T (2011) Annotated catalogue of Enicocephalomorpha, Dipsocoromorpha, Nepomorpha, Gerromorpha, and Leptopodomorpha (Hemiptera: Heteroptera) of Turkey, with new records. Zootaxa 2856: 1-84.

Golub NV, Golub VB, Kuznetsova VG (2015) Localization of 18rDNA loci in four lace bug species (Hemiptera, Tingidae) with the same chromosome number. Comparative Cytogenetics 9(4): 513-522. doi: 10.3897/CompCytogen.v9i4.5376

Grozeva SM, Nokkala S (1996) Chromosomes and their meiotic behavior in two families of the primitive infraorder Dipsocoromorpha (Heteroptera). Hereditas 125: 31-36. doi: 10.1111/j.1601-5223.1996.t01-1-00031.x

Grozeva S, Nokkala S (2002) Achiasmatic male meiosis in Cimex sp. (Heteroptera, Cimicidae). Caryologia 55(3): 189-192. doi: 10.1080/00087114.2002.10589276

Grozeva S, Simov N, Nokkala S (2008) Achiasmatic male meiosis in three Micronecta species (Heteroptera: Nepomorpha, Micronectidae). Comparative cytogenetics 2(1): 73-78. 
Hädicke CW (2012) Die Mundwerkzeuge der Corixoidea (Börner, 1935) (Heteroptera: Nepomorpha) und deren Evolution. Mitteilungen der Deutschen Gesellschaft für allgemeine und angewandte Entomologie 18: 99-106.

Hebsgaard MB, Andersen NM, Damgaard J (2004) Phylogeny of the true water bugs (Nepomorpha: Hemiptera-Heteroptera) based on $16 \mathrm{~S}$ and 28S rDNA and morphology. Systematic Entomology 29(4): 488-508. doi: 10.1111/j.0307-6970.2004.00254.x

Hutchinson GE (1940) A revision of the Corixidae of India and adjacent regions. Transactions of the Connecticut Academy of Arts and Sciences 33: 339-476.

Ituarte S, Papeschi AG (2004) Achiasmatic male meiosis in Tenagobia (Fuscagobia) fuscata (Stål) (Heteroptera, Corixoidea, Micronectidae). Genetica 122: 199-206. doi: 10.1023/B:GE NE.0000041048.75715.68

Jansson A (1973) Stridulation and its significance in the genus Cenocorixa (Hemiptera, Corixidae). Behaviour 46(1): 1-36. doi: 10.1163/156853973X00157

Jansson A (1986) The Corixidae (Heteroptera) of Europe and some adjacent regions. Acta Entomologica Fennica 47: 1-94.

Konopko SA, Mazzucconi SA, Bachmann AO (2010) Description of the nymphs of Tenagobia (Incertagobia) incerta Lundblad 1929 and Tenagobia (Schadeogobia) schadei Lundblad 1929 (Hemiptera: Heteroptera: Micronectidae), with emphasis on morphometry and chaetotaxy. Zootaxa 2511: 39-58.

Kuznetsova V, Grozeva S, Nokkala S, Nokkala C (2011) Cytogenetics of the true bug infraorder Cimicomorpha (Hemiptera, Heteroptera): a review. Zookeys 154: 31-70. doi: 10.3897/ zookeys.154.1953

Kuznetsova VG, Grozeva S, Sewlal JN, Nokkala S (2007) Cytogenetic characterization of the endemic of Trinidad, Arachnocoris trinitatus Bergroth: the first data for the tribe Arachnocorini (Heteroptera: Cimicomorpha: Nabidae). Folia Biologica (Kraków) 55 (1-2): 17-26. doi: $10.3409 / 173491607780006344$

Mahner M (1993) Systema cryptoceratum phylogeneticum (Insecta, Heteroptera). Zoologica 143: 1-303.

Nieser N (2002a) Four new species of Micronecta from the Malay Peninsula. Raffles Bulletin of Zoology 50(1): 9-16.

Nieser N (2002b) Guide to aquatic Heteroptera of Singapore and peninsular Malaysia. IV. Corixoidea. The Raffles Bulletin of Zoology 50(1): 263-274.

Nokkala S (1986) The mechanisms behind the regular segregation of the m-chromosomes in Coreus marginarus L. (Coreidae, Hemiptera). Hereditas 105: 73-85. doi: 10.1111/j.16015223.1986.tb00645.x

Nokkala S, Grozeva S (2000) Male meiosis of achiasmatic type in Myrmedobia coleoptrata (Fn.) (Heteroptera, Microphysidae). Caryologia 53(1): 5-8. doi: 10.1080/00087114.2000.10589176

Nokkala S, Nokkala C (1983) Achiasmatic male meiosis in two species of Saldula (Saldidae, Hemiptera). Hereditas 99: 131-134. doi: 10.1111/j.1601-5223.1983.tb00737.x

Nokkala S, Nokkala C (1984) Achiasmatic male meiosis in the Heteropteran genus $\mathrm{Na}$ bis (Nabidae, Hemiptera). Hereditas 101: 31-35. doi: 10.1111/j.1601-5223.1984. tb00445.x 
Nokkala S, Nokkala C (1986a) Achiasmatic male meiosis of collochore type in the heteropteran family Miridae. Hereditas 105: 193-197. doi: 10.1111/j.1601-5223.1986.tb00661.x

Nokkala S, Nokkala C (1986b) Achiasmatic male meiosis in Anthocoris nemorum (L.) (Anthocoridae, Hemiptera). Hereditas 105: 287-289. doi: 10.1111/j.1601-5223.1986. tb00675.x

Nokkala C, Kuznetsova V, Nokkala S (2015) Rare diploid females coexist with rare males: a novel finding in triploid parthenogenetic populations in the psyllid Cacopsylla myrthili (W. Wagner, 1947) (Hemiptera, Psylloidea) in northern Europe. Genetica 143(5): 589-595. doi: 10.1007/s10709-015-9858-x

Schuh RT, Slater JA (1995) True Bugs of the World (Hemiptera: Heteroptera). Classification and Natural History. Cornell University Press, Ithaca, New York, 336 pp.

Slack HD (1938) The association of non-homologous chromosomes in Corixidae (HemipteraHeteroptera). Proceedings of the Royal Society, Edinburgh, Series B 58: 192-212.

Southwood TRE, Leston D (1959) Land and Water Bugs of the British Isles. Frederick Warne \& Co. Ltd., London, 436 pp.

Štys P, Jansson A (1988) Check-list of recent family-group and genus-group names of Nepomorpha (Heteroptera) of the world. Acta Entomologica Fennica 50(1): 1-44.

Tinerella PP (2008) Taxonomic revision and systematics of New Guinea and Oceania pygmy water boatmen (Hemiptera: Heteroptera: Corixoidea: Micronectidae). Zootaxa 1797: 1-66.

Ueshima N (1979) Hemiptera II, Heteroptera. Animal Cytogenetics 3 Insecta 6. Gebrüder Borntraeger, Stuttgart, $117 \mathrm{pp}$.

Waller MS, Angus RB (2005) A chromosomal investigation of the west European species of Corixa Geoffroy (Heteroptera). Genetica 125(1): 17-25. doi: 10.1007/s10709-005-1468-6

Weirauch C, Schuh RT (2011) Systematics and Evolution of Heteroptera: 25 Years of Progress. Annual Review of Entomology 56: 487-510. doi: 10.1146/annurev-ento-120709-144833

White MJD (1973) Animal Cytology and Evolution. Cambridge University Press, Cambridge, $961 \mathrm{pp}$.

Zimmermann G (1986) Zur Phylogenie der Corixidae Leach, 1815 (Hemiptera, Heteroptera, Nepomorpha). Dissertation, Universität Marburg, 294 pp. 